\title{
In Vivo Desflurane Preconditioning Evokes Dynamic Alterations of Metabolic Proteins in the Heart - Proteomic Insights Strengthen the Link between Bioenergetics and Cardioprotection
}

\author{
Nadine Dyballa-Rukes ${ }^{a}$ Christian Schuh ${ }^{a}$ Hendrik Vogt ${ }^{a}$ Octavian Toma $^{b}$ \\ Wolfgang S. Schlack ${ }^{b}$ Nina C. Weber ${ }^{c}$ Sabine Metzger ${ }^{a, d}$ \\ aBiological Medical Research Centre, Heinrich-Heine-University of Düsseldorf, Düsseldorf, Germany; \\ ${ }^{b}$ Department of Anaesthesiology, 'Laboratory of Experimental Intensive Care and Anaesthesiology, \\ Academic Medical Centre, University of Amsterdam, Amsterdam, The Netherlands; ${ }^{\mathrm{d} C u r r e n t}$ address: \\ University of Cologne, Biocenter, Cologne
}

\section{Key Words}

Proteomics • Volatile anaesthetics $•$ Desflurane $\cdot$ Preconditioning $\bullet$ Protein remodelling

\begin{abstract}
Background: The cardioprotective effect of anaesthetic preconditioning as measured by reduction of ischaemia-reperfusion (I/R) injury is a well described phenomenon. However little is known about the impact on the myocardial proteome. We therefore investigated proteome dynamics at different experimental time points of a preconditioning protocol. Methods: Using an in vivo rat model of desflurane-induced preconditioning (DES-PC) cardiac tissue proteomes were analysed by a gel-based comparative approach. Treatment-dependent protein alterations were assessed by intra-group comparisons. Proteins were identified by mass-spectrometry. Results: A total of 40 protein spots were altered during the 30 -minutes lasting preconditioning protocol. None of the proteins was differentially regulated consistently at all experimental time points. Interestingly, 1) the repeated administration of desflurane mostly accounted for proteome alterations during DES-PC, 2) the majority of altered protein species showed a decrease in abundance, 3 ) these changes primarily affected metabolic proteins involved in $\mathrm{NADH} / \mathrm{NAD}^{+}$redox balance, calcium homeostasis and acidosis and 4) protein alterations were not exclusively due to expression changes but also represented modifications of specific protein isoforms. Conclusion: DES-PC evokes dynamic alterations in the cardiac proteome which substantiate a tight regulation of bioenergetic proteins. Unique protein modifications may play a more important role in the preconditioning response.
\end{abstract}

Copyright @ 2014 S. Karger AG, Basel 


\section{Introduction}

Cardiac preconditioning is a powerful intervention that can protect the heart against severe ischaemia-reperfusion (I/R) injuries. Modern volatile anaesthetics as elicitors of cardiac preconditioning have been effectively demonstrated in cell culture experiments [1, 2] and animal models [3-6]. There is also supporting evidence from clinical studies that anaesthetic-induced preconditioning (APC) is protective in the clinical setting [7-9]. In general, a typical preconditioning protocol consists of one or more cycles of agent application plus washout-phase whereby some variations exist among the used models.

When comparing the potential of the volatile anaesthetics desflurane, sevoflurane, isoflurane and halothane to induce preconditioning in the rabbit myocardium, desflurane preconditioning (DES-PC) was found to be the most potent stimulus [10]. Subsequent molecular investigations of DES-PC were conducted with focus on specific targets known from IPC $[2-5,11,12]$ but the overall picture of the underlying mechanisms is still lacking. A couple of studies even showed that the signalling pathways may differ from IPC $[6,13]$.

Discovery-driven proteomics studies allow for the relative comparison of protein expression from very large data sets to unravel significant correlations between e.g. myocardial tissue specimens. Nevertheless, proteomics approaches investigating the effect of APC remain scarce, and the three conducted studies exclusively examined the mitochondrial proteome after single-cycle exposure of isoflurane or sevoflurane [14-16]. Whether other proteins like cytosolic ones were changed was not determined. Moreover, nothing is known about the unique protein profiles at each experimental point of the preconditioning protocol. It may be more important to analyse expression changes at the different points of administration and washout-phase separately. In the present study we therefore examine the time course profiles of cardiac subproteomes in response to DES-PC in vivo using a gelbased proteomics approach with conceptual refinements.

\section{Materials and Methods}

\section{Desflurane preconditioning protocol}

The animal experiments were conducted in accordance with the regulations of the German Animal Protection Law and were approved by the Bioethics Committee of the District of Düsseldorf, North RhineWestphalia, Germany (G18/04; 50.05-230-18/04). Anaesthetic preconditioning of male Wistar rats (250 - $300 \mathrm{~g}$ ) was performed using desflurane (Baxter Deutschland GmbH, Unterschleissheim, Germany) as described by Toma and co-workers [5]. The application of 1 MAC desflurane in Wistar rats corresponded to $6.9 \%$ of the inspired gas.

For the analysis of proteomic changes in the time course of DES-PC, rats were randomly assigned to

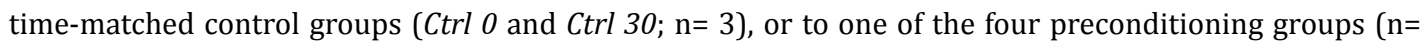
3-4): after the first (DES 1) and second administration of 1 MAC desflurane (Des 2), and after the first (Wash 1) and last washout-phase (Wash 2) (Fig. 1). After excision, heart tissue was briefly washed with $0.9 \% \mathrm{NaCl}$ to remove residual blood, shock-frozen in liquid nitrogen and stored at $-78^{\circ} \mathrm{C}$ until use (for a maximum duration of one year).

\section{Preparation of heart tissue samples}

Frozen heart tissue was pulverised between two nitrogen-cooled metal blocks (Dick, Deizisau, Germany), suspended in lysis buffer containing $5 \mathrm{mM}$ Tris base, $2 \mathrm{mM}$ EGTA, $2 \mathrm{mM} \mathrm{Na}_{3} \mathrm{VO}_{4}, 50 \mathrm{mM} \mathrm{NaF}, 0.2$ $\mu \mathrm{M}$ okadaic acid, aprotinin, pepstatin A and leupeptin (each $0.01 \%(\mathrm{w} / \mathrm{v}$ ) in $500 \mathrm{mM}$ Tris-HCl (pH 7.4)), and homogenised using a motorised blender with different shear force adaptors (IKA, Staufen, Germany). The homogenate was centrifuged at $1000 \mathrm{~g}$ at $4^{\circ} \mathrm{C}$ for ten minutes. The supernatant containing the crude aqueous-soluble fraction was centrifuged again at $16000 \mathrm{~g} 4^{\circ} \mathrm{C}$ for 15 minutes to clean up cytosolic proteins. The remaining pellet of the first centrifugation step was solubilised in Tris-lysis buffer containing additionally $1 \%(\mathrm{v} / \mathrm{v})$ Triton X-100. The sample was incubated for one hour on ice and then centrifuged at $16000 \mathrm{~g}$ at $4^{\circ} \mathrm{C}$ for 15 minutes. The resulting supernatant contained the detergent-soluble fraction including 
mitochondrial and membrane-associated proteins. Protein concentrations were separately determined for each protein fraction by the Lowry protein assay [17] using BSA as a standard.

Protein fractions were further purified by precipitation using TCA and acetone. Samples (100-150 $\mu \mathrm{g}$ protein) were incubated with $10 \%$ TCA in 8 volumes ice-cold acetone (80\%) for a minimum of 2 hours at $-20^{\circ} \mathrm{C}$. Protein precipitates were collected by centrifugation at $16000 \mathrm{~g}$ for 45 minutes at $4^{\circ} \mathrm{C}$, washed twice with ice-cold acetone (80\%) and finally air-dried to remove residual acetone.

Two-dimensional gel electrophoresis (2-DE): Isoelectric focussing (IEF) and SDS-PAGE

To enhance the resolution of acidic-neutral proteins on the one hand and alkaline proteins on the other hand partially overlapping $\mathrm{pH}$ gradient strips ( $\mathrm{pH}$ 4-7 and $\mathrm{pH}$ 6-11) were used for first dimension separation during 2-DE. Proteins to be analysed in the neutral-acidic $\mathrm{pH}$ range were solubilised in $7 \mathrm{M}$ urea, $2 \mathrm{M}$ thiourea, 2\% CHAPS, $40 \mathrm{mM}$ DTT and 0.5\% IPG Buffer (GE Healthcare) for at least 1 hour to ensure complete denaturation and solubilization, and applied to IPG strips 4-7 overnight by ingel rehydration. IEF was performed using the IPGphor system (GE Healthcare) for a total of $9.5 \mathrm{kVhours,}$ following a standard focusing protocol with slight modifications [300 V for 1 hour (step and hold), $1000 \mathrm{~V}$ in 0.5 hours (gradient mode), $2400 \mathrm{~V}$ in 1.5 hours (gradient mode) and $2400 \mathrm{~V}$ for 1 hour (step and hold)]. For the analysis of alkaline proteins samples were solubilised in $7 \mathrm{M}$ urea, 2 M thiourea, 1\% CHAPS, 1\% ASB-14, $50 \mathrm{mM}$ HED and 2\% IPG Buffer for at least 1 hour and applied to already rehydrated IPG strips pH 6-11 by cup-loading near the anode. IEF was performed in the Multiphor electrophoresis system (GE Healthcare). To avoid protein aggregation at the sample application point and to overcome restricted protein load, the cups were refilled repetitively with diluted samples. Proteins were focused for a total of $11.1 \mathrm{kVhours} \mathrm{[500}$ $\mathrm{V}$ for 2 hours (step and hold), $1500 \mathrm{~V}$ in 2 hours (gradient mode), $3500 \mathrm{~V}$ for 1.5 hours (gradient mode) and $3500 \mathrm{~V}$ for 1.5 hours (step and hold)].

Upon completion of IEF the strips were subjected to reduction and alkylation using 1\% DTT and 2.5\% iodoacetamide respectively in equilibration solution [6 M urea, $50 \mathrm{mM}$ Tris- $\mathrm{HCl}$ (pH 8.8), 30\% glycerol and $2 \%$ SDS]. Second dimension separation was performed by SDS-PAGE on vertical electrophoresis systems $(10 \times 10 \mathrm{~cm})$ with a total acrylamide concentration of 10-12\%, depending on the subproteome investigated (see legends of Fig. 2). Proteins were separated for 2.5 hours, starting at $100 \mathrm{~V}$ for 15 minutes followed by $120 \mathrm{~V}$ until the dye front reached the bottom of the gel. Each sample was run in triplicate but not in batch to factor differences due to technical variations.

Proteins were visualized using the colloidal Coomassie G-250 staining protocol according to Kang and co-workers [18] with slight modifications [19]. Gels were stained overnight [0.02\% CBB G-250, 5\% aluminium sulphate, $10 \%$ ethanol and $2 \%$ orthophosphoric acid] and briefly destained [10\% ethanol and $2 \%$ orthophosphoric acid] for 15 minutes before image acquisition. Stained gels were digitised at $300 \mathrm{dpi}$ via the Labscan Software version 5.0 using the ImageScanner (both GE Healthcare).

\section{Phosphospecific protein stain}

A fluorescent stain (Pro-Q® Diamond Phosphoprotein Gel Stain) was used to detect phosphorylated proteins in 2-DE gels. The staining was performed according to the manufacturer's standard protocol (Molecular Probes, Eugene, USA). The gel was immersed in fixing solution [50\% methanol, 10\% acetic acid] and incubated with gentle agitation for 30 minutes. The fixation step was repeated overnight to ensure washout of residual SDS. Following three washing steps of 10 minutes each, gels were stained with ProQ Diamond for 1.5 hours in the dark, and destained by 3 x 30-minute washes using a solution containing 20\% acetonitrile, $50 \mathrm{mM}$ sodium acetate ( $\mathrm{pH} 4.0$ ). ProQ Diamond stained gels were scanned on a Typhoon 9400 variable mode imager (GE Healthcare) at 480V / 200 microns (excitation source $532 \mathrm{~nm}$ laser; emission filter $560 \mathrm{~nm}$ longpass).

\section{Statistical gel analysis}

Computer based analysis of the 2-DE gels including spot detection, normalisation, matching and statistics was performed using the Image Master 2D Platinum Software version 7.02 (GE Healthcare). Spot quantification was determined on the basis of relative spot volume [\%Vol.]. To avoid errors due to a lower technical reproducibility close to the limit of detection, a minimal spot value of $0.015 \%$ Vol. was imposed for further data analysis. Data was validated by excluding expression changes that resulted from the surgical situation (\%Vol. of Ctrl 0 vs. Ctrl 30). Intra-group variances were comprised via scatter plot analysis 


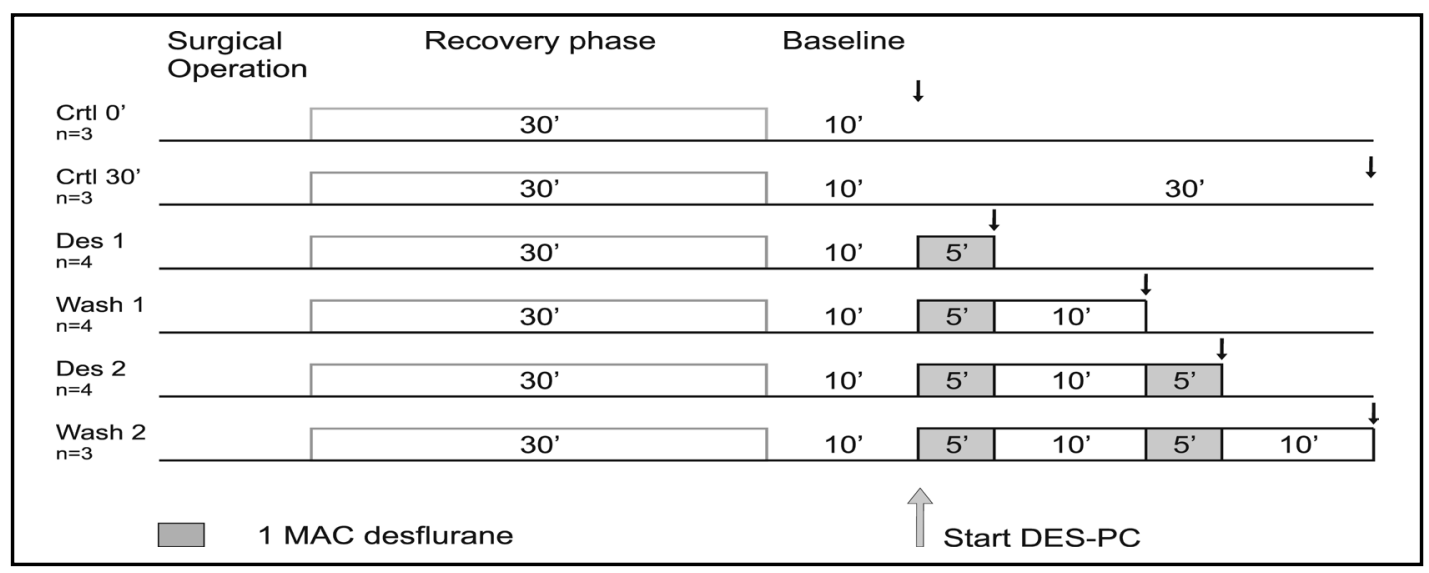

Fig. 1. Experimental protocol of in vivo cardiac preconditioning using desflurane. To study proteomic changes during the time course of desflurane-preconditioning male Wistar rats were randomly assigned to one of the four DES-PC groups: Des 1 received 1 MAC desflurane, Wash 1 received 1 MAC desflurane and underwent a washout phase, Des 2 received a repetitive administration of 1 MAC desflurane interspersed by a washout phase, and Wash 2 received twice a desflurane application and two washout phases. Untreated animals were used as time-matched controls for the starting (Ctrl O) and ending point (Ctrl 30) of the preconditioning protocol. Heart tissue was excised at the respective time points indicated by arrows.

$\left(\mathrm{R}^{2}=0.98\right.$ and 0.90 for in-gel rehydration and cup-loading experiments, respectively). The coefficient of variation was determined for control groups and accounted as favourable as $26.4 \%$ for samples applied via in-gel rehydration and $39.6 \%$ for the cup-loading method. Using descriptive statistics spot pairs with overlapping differences between the treatment groups were rejected to avoid type 1 errors. Variations in protein expression were calculated by a relative abundance ratio in \%Vol. of 1.2-fold for spot pairs (each time point of DES-PC vs. Ctrl 0 ). With regard to the limited number of experimental animals the threshold for a meaningful and representative statistic analysis was set to $P<0.02$ (ANOVA).

\section{Protein identification by ESI-MS/MS}

Protein spots of interest were excised from Coomassie stained gels, completely destained and incubated with $0.1 \mu \mathrm{g} / \mu \mathrm{l}$ proteomics grade trypsin (Sigma-Aldrich) in $25 \mathrm{mM}$ ammonium bicarbonate (pH 8.0) for 12 - 16 hours at $37^{\circ} \mathrm{C}$. The eluted peptides (pooled from supernatant and extracted from gel plug by washing with $50 \%$ ACN / 5\% formic acid) were dried in a vacuum centrifuge (Eppendorf, Hamburg, Germany) and stored at $-20^{\circ} \mathrm{C}$ until analysed by ESI-MS/MS. The peptides were then reconstituted in $4 \%$ methanol / 1\% formic acid and desalted using a reversed-phase PerfectPure C-18 Tip (Eppendorf). Peptides were eluted in $60 \%$ methanol / 1\% formic acid and immediately analysed by ESI tandem mass spectrometry using an ESI Qq-TOF instrument equipped with a nanospray source (Q-STAR XL, Applied Biosystems, Darmstadt, Germany). Using Analyst QS version 1.1 (Applied Biosystems) full MS scans from 350 to 1500 $\mathrm{m} / \mathrm{z}$ were acquired and at least five peptides per sample were subjected to further fragmentation. Protein identification was performed using the BioAnalyst 3.0 software (Applied Biosystems) by searching the NCBI database. Following parameters were set for the MASCOT search (version 1.6b13, Matrix Science, London, United Kingdom): protease: trypsin; missed cleavages: 1; variable modifications: carbamidomethyl (C) and oxidation (M); peptide tolerance: $\pm 1.2 \mathrm{Da}$; MS/MS tolerance: \pm 0.6 Da. Protein identification was considered positive when at least 3 peptides were assigned to the protein or protein sequence coverage achieved > $12 \%$.

\section{Results}

Fractionation strategy for improved proteome analyses

To gain a more global view of the underlying mechanisms, in particular during the time course of preconditioning, we determined the proteomic response of the heart at different 
Fig. 2. Fractionation strategy for in-depth proteome profiling. A sequential extraction procedure with increasing solubilisation power was applied to gain cytosolic (A) and membrane-associated protein fractions (B). The resolution of acidic-neutral proteins on the one hand (C) and alkaline proteins on the other hand (D) was improved by IEF in partially overlapping $\mathrm{pH}$ gradient strips (pH 4-7 and 6-11). This fractionation strategy allowed the detection of proteins of low abundance (D, indicated by an arrow) or of extreme pI's (D, encircled protein spot). The respective $\mathrm{pH}$ gradients are indicated at the top of each gel, with molecular weight (in $\mathrm{kDa}$ ) of protein standards

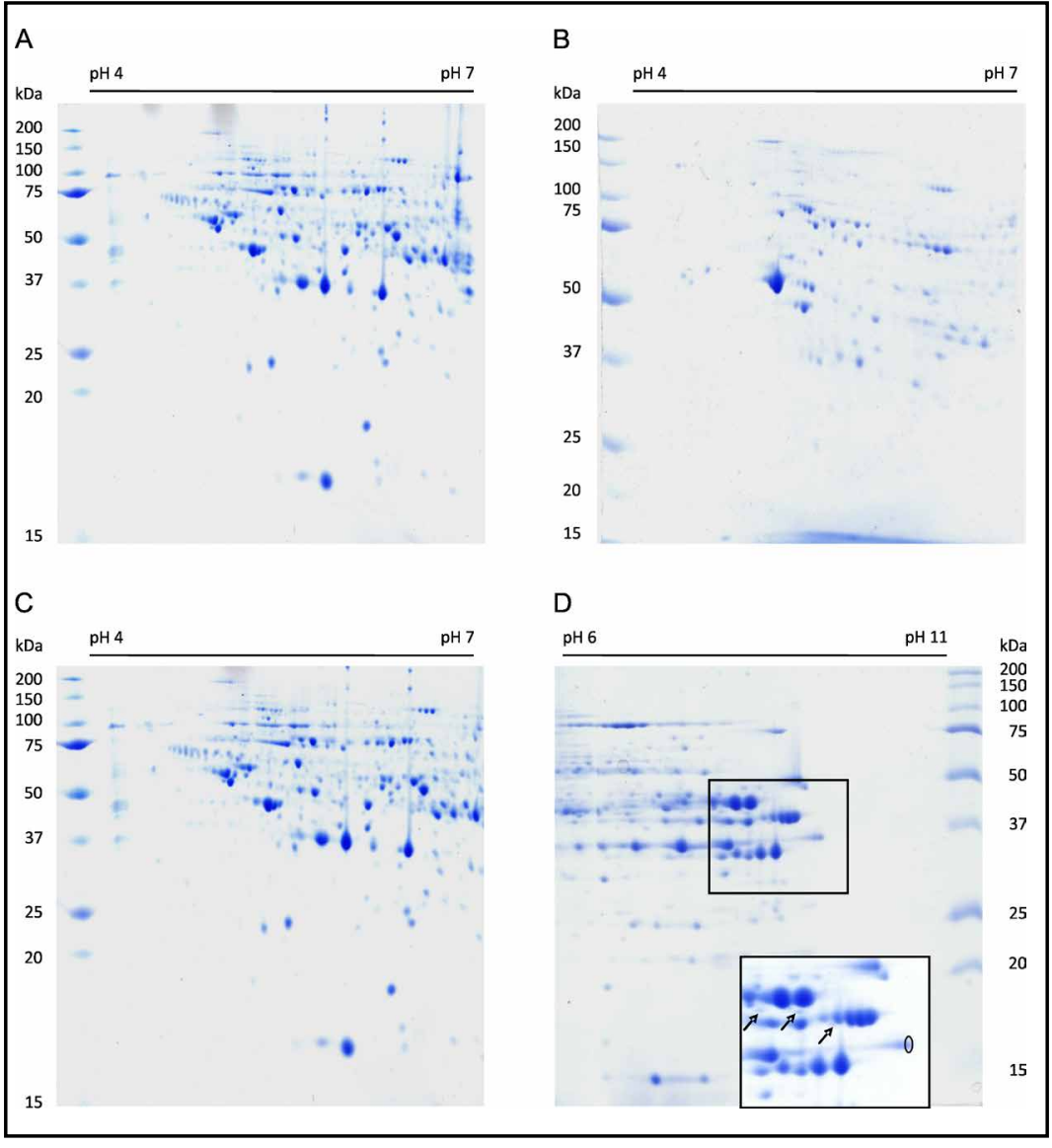
outside the separation area. Detergent-soluble proteins (pH range 4-7) were separated in 10\% polyacrylamide gels, water-soluble proteins (pH range 4-7) in 11\% and water-soluble proteins $\mathrm{pH}$ range 6-11 in $12 \%$ polyacrylamide gels.

experimental time points of DES-PC in depth. We chose a bottom-up approach using the high resolution capacity of two-dimensional gel electrophoresis (2-DE) that allows on the one hand to examine rapid protein expression changes from a large series of experiments (here 21 independent data points: 6 control individuals and 15 treatment individuals) and on the other hand to handle complete proteins including modification events of protein isoforms. For better subproteome profiling, pre-fractionation of proteins was conducted according to their solubility properties (Fig. 2A+B) as well as to their chemical isoelectric point (pI) (Fig. $2 \mathrm{C}+\mathrm{D})$.

This strategy enabled us to observe proteins from cardiac tissue samples that even are in low abundance or of extreme pI. For instance low-abundant protein spots (indicated by arrows in Fig. 2D) could be co-detected with high abundant proteins, and the most basic spot (encircled in the enlarged area of Fig. 2D) was identified as succinyl CoA ligase, $\alpha$ subunit (theoretical pI 9.9).

\section{Analysis of proteome alterations during DES-PC}

Each pre-fractionated subproteome was analysed separately, resulting in a total of 40 protein spots which were affected during the 30-minutes lasting preconditioning protocol (1.2-fold, $P<0.02$ vs. Ctrl 0 ). It is noticeable that none of the proteins was differentially regulated consistently at all experimental time points. Most protein spots were significantly regulated only once during DES-PC (6 up- and 20 down-regulated), whereas 13 protein spots showed abundance changes at several experimental time points ( 1 up- and 12 downregulated). For one protein spot we even observed a contrarian alteration during the course 
Fig. 3. Global protein expression changes during DES-PC. Number of unique protein spots that showed a 1.2-fold change in abundance ratio [\%Vol.] vs. Ctrl $0(P<0.02$; ANOVA $)$ given for increased and decreased expression separately. Inter-group comparisons (DES-PC treatment points vs. Ctrl 0 ) of the different subproteomes water- and detergent-soluble as well as acidic-neutral and alkaline protein fractions (altogether $\sim 550$ spot matches analyzed) revealed a cumulative response of the myocardial proteome to the desflurane application.

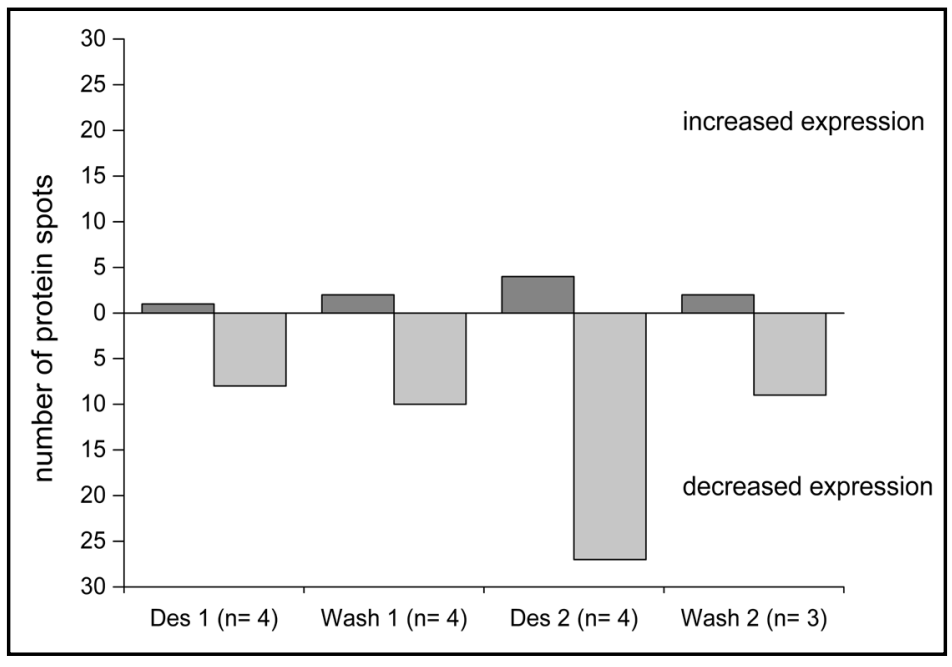

of DES-PC. It is noticeable that the majority of proteins predominantly responded to the second preconditioning stimulus Des 2 compared to control (Fig. 3). The data indicate a cumulative effect in view of the fact that the repeated administration of desflurane evoked more abundance changes than the first dose.

Among these 40 protein spots with changed abundance, 14 were identified by ESIMS/MS revealing 12 non-redundant proteins (Table 1). Based on the annotations of the NCBInr database they were functionally classified into categories with regard to their biological processes. Categorisation was based on the PANTHER (Protein ANalysis THrough Evolutionary Relationships) classification system http://www.pantherdb.org and revealed that 11 out of 12 proteins are mitochondrial-encoded or mitochondrial precursor proteins representing metabolic enzymes involved in aerobic metabolism, or enzyme subunits with a wide spectrum of catalytic and regulatory activities. The identified proteins are associated with amino acid metabolism aminoaspartate transferases (AST1 and AST2) as well as methylmalonate-semialdehyde dehydrogenase (MMSADH). A couple of proteins belong to the electron transport such as NADH-ubiquinone oxidoreductase 75kDa subunit (NDUFS1) and ubiquinol-cytochrome $c$ reductase core protein 1 (UQCRC1). The carboanhydrases (CA1 and CA2) participate in the metabolism of hydrocarbons and phenolic compounds that are not proteins or lipids. Other metabolic proteins contribute to oxidative phosphorylation like NADH dehydrogenase ubiquinone flavoprotein 1 (NDUFV1), or to glycolysis like L-lactate dehydrogenase (LDH-B). Aconitase 2 (ACO2) is a major player in the Krebs cycle and inorganic pyrophosphatase (PPA2) belongs to the polyphosphate catabolism. The only nonmetabolic protein, albumin (ALB), is associated with transportation processes.

Metabolic proteins follow different treatment-dependent modulation during DES-PC

The majority of identified proteins were significantly altered just at one experimental time point during DES-PC (Fig. 4). In fact the second administration of 1 MAC desflurane (Des 2) accounted for eight out of the 14 identified protein alterations (AST1, AST2 (spot \#16 and \#59), ACO2, MMSADH, NDUFS1, CA2 (spot\#129) and ALB). The other four proteins (NDUFV1, UQCRC1, CA2 (spot \#130) and PPA2) were affected at several time points of the DES-PC protocol, and except for PPA2 all including treatment point Des 2 . The two protein spots that did not directly respond to Des 2 (CA1 and LDH-B) showed decreased abundance exclusively at the end of the preconditioning protocol.

The identified protein spots can be distinguished into clusters of treatment-dependent modulation (Fig. 4). The AST isoforms, that were the only ones with increased abundance during DES-PC, showed a substantial increase after the first preconditioning stimulus (Des 1) with a maximum significant response at experimental time point Des 2 , and a rapid 


\begin{tabular}{|c|c|c|}
\hline Cell & Cell Physiol Biochem 2014;33:967-981 & \\
\hline and Biochemistry & $\begin{array}{l}\text { DoI: 10.1159/000358668 } \\
\text { Publisned online: Marcn } 31,2014\end{array}$ & $\begin{array}{l}\text { O } 2014 \text { S. Karger AG, Basel } \\
\text { www.karger.com/cpb }\end{array}$ \\
\hline
\end{tabular}

Table 1. Characteristics of DES-PC responding proteins identified by ESI-MS/MS. Proteins are arranged in functional groups according to the PANTHER classification system. Spot numbers match to Figure 4. Full and abbreviated names are given. Molecular weight $\left(\mathrm{M}_{\mathrm{r}}\right)$ and $\mathrm{pI}$ were calculated using the GPMAW program (version 9.02, Lighthouse data, Odense, Denmark) and experimentally determined from 2-DE gels. Number of peptides sequenced by ESI-MS/MS. Sequence coverage was calculated from MS/MS fragmentation using GPMAW. Black arrows in the image sections indicate the identified protein spots; coloured arrows indicate the expression changes at the respective treatment point of DES-PC and refer to Figure $4 .{ }^{\S}$ single-peptidebased identification was performed in accordance to the Paris guidelines for proteomics data

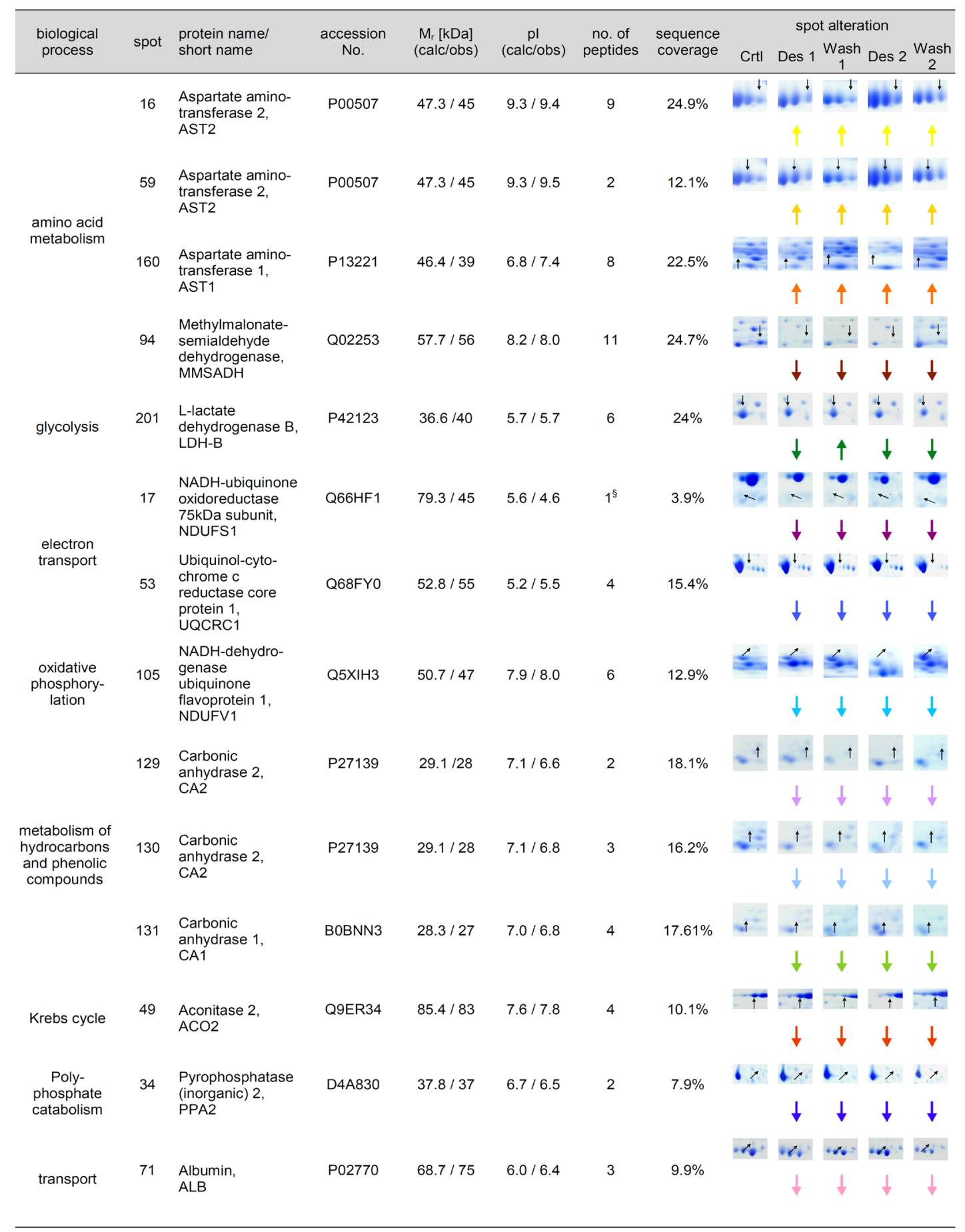



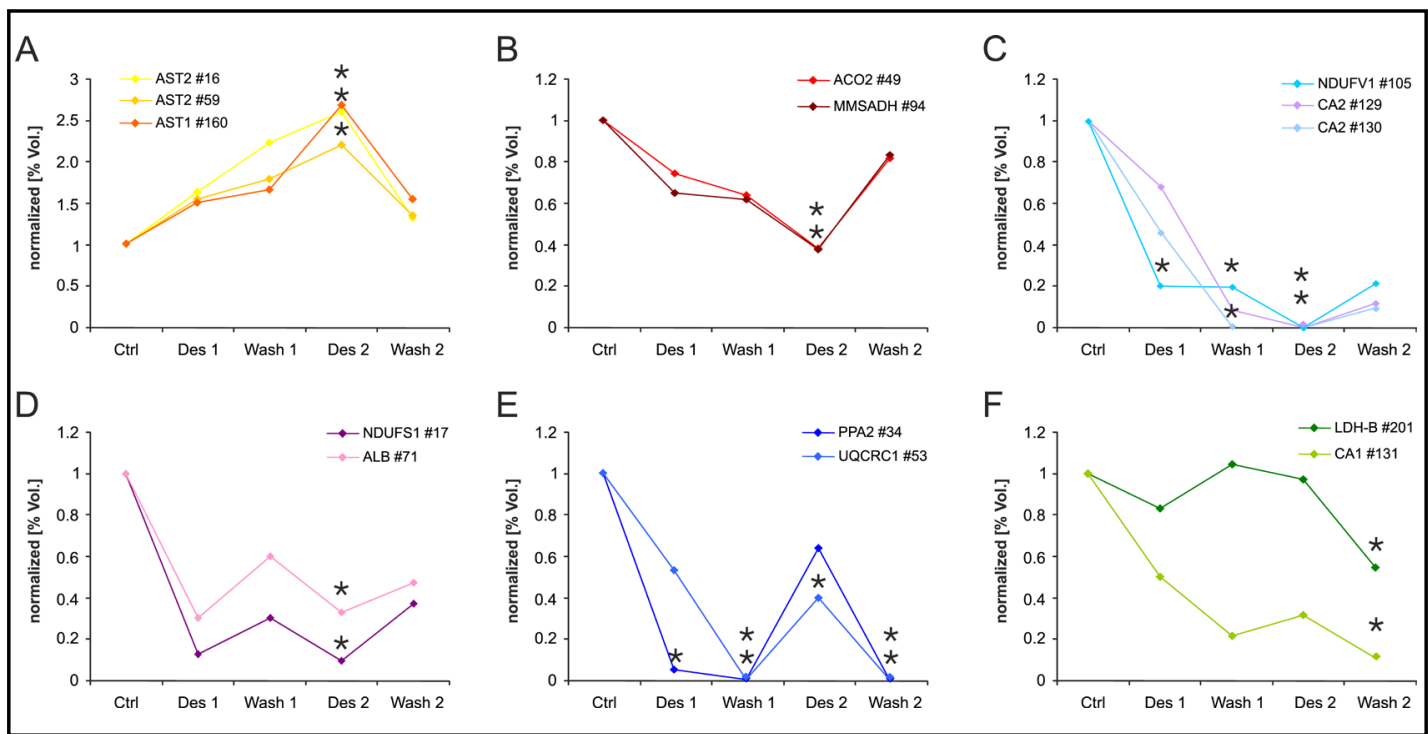

Fig. 4. Modulation of differentially expressed protein isoforms during the time course of DES-PC. The 14 identified proteins and protein isoforms (with at least one significant expression change during DES-PC) were combined into clusters of uniform expression pattern to unravel inter-individual treatment-dependent responses. (A) Proteins with higher levels following DES-PC. (B-F) Proteins with reduced abundance during DES-PC. For better visual representation of similar modulation only normalized means are given (based on relative levels in Ctrl 0 group set to $1 ;{ }^{*} P<0.02$ ). Expression changes are represented as normalized values [\%Vol.] relative to control ( $\operatorname{Ctrl} 0 \mathrm{n}=3$; DES-PC treatment points $n=3-4)$; data are Mean $(100 \%)$ and M.S.D; level of statistical significance (1.2-fold ratio change, $P<0.02$ ANOVA) compared to control (Ctrl 0 ) is indicated by an asterisk. Abbreviations refer to identified proteins in Table 1 . The graphs sum up the analyses of three independent experiments.

drop down in expression following the second wash-out phase (Wash 2). It is noticeable that their expression status returned close to control levels of abundance at the end of the protocol (Fig. 4A). The other protein spots which decreased in abundance in at least one of the four experimental time points of DES-PC considerably differed in their course during the preconditioning protocol. ACO2 and MMSADH followed the same modulation like the ASTs but mirror-inverted, namely a continuous decrease until Des 2 where they reached a significant decline in abundance, which is then followed by an immediate increase nearly to baseline levels (Fig. 4B). The analogue decrease of NDUFV1 and the CA2 spots during DES-PC is that intense that they totally vanish at Des 2 but slightly reappeared at the end of the preconditioning protocol at time point Wash 2 (Fig. 4C). The protein spots of NDUFS1 and ALB in Figure 4D featured also a similar modulation but were represented by a more cluttered course up and down that apparently showed a trend in terms of increasing response to the desflurane administrations. Likewise did PPA2 and UQCRC1 but they seemed to be primarily decreased to a greater extend after the washout phases as shown in Figure 4E. LDH-B and CA1 were significantly altered exclusively at the end of the preconditioning protocol, after the second washout phase Wash 2 (Fig. 4F). Following the first desflurane stimulus a rapid signalling transmission with the same tendency toward significance levels was observed. However it is hard to say if the signalling of the respective protein isoforms took place concurrently or successively. Solely the decrease of LDH-B might be specified as a downstream event.

\section{Remodelling effect of protein spot isoforms during DES-PC}

Several DES-PC responding proteins existed in so-called charge trains, and expression changes appeared only for specific and not for all spots of the respective protein. Using the example of AST2, the significant abundance changes were only detected for the two acidic 
Fig. 5. Different remodelling effects of specific spot isoforms within protein charge trains during DES-PC. (A): Representative spot chain of multiple spot isoforms of AST2 at baseline levels ( $\mathrm{Ctrl} 0$ ). Analysis of protein volume data of AST2 spot isoforms allowed to distinguish between expression changes of the whole protein and significant alterations of the acidic protein variants $(\# 16+59)$. (B): Multiple pI variants of UQCRC1 at baseline levels ( $\mathrm{Ctrl} 0$ ). 2-DE gel staining with Coomassie (upper panel) and phosphospecific protein staining (lower panel)

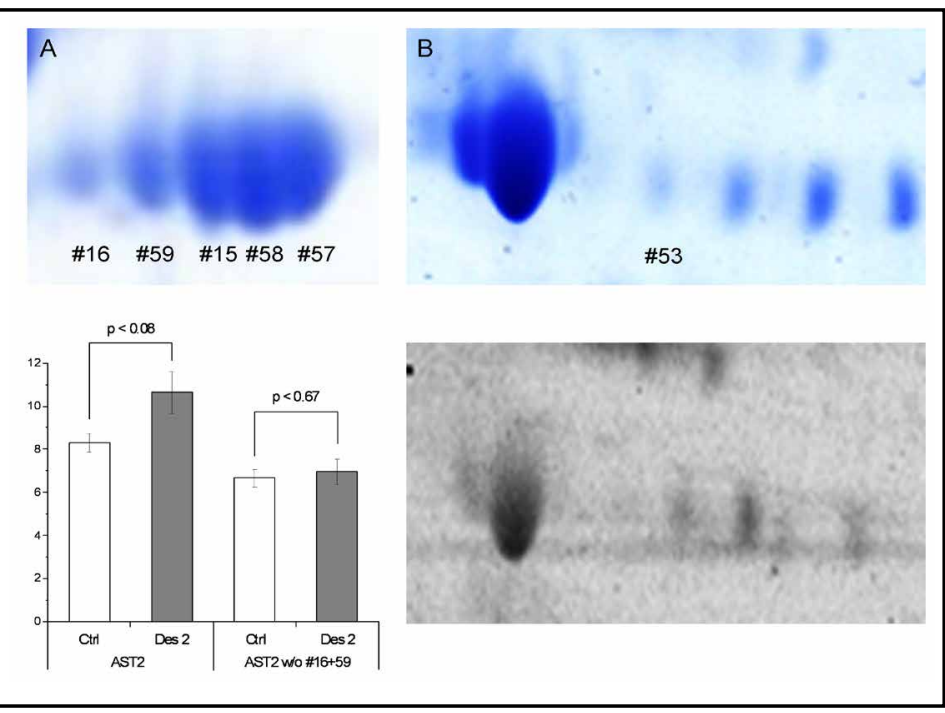
revealed a phosphorylation pattern for UQCRC1. Protein isoforms of interest are labeled with the respective spot number.

spots of the protein chain (spot\#16 and \#59, Fig. 5A). Both spot isoforms showed significantly increased expression after the second desflurane administration. Interestingly, the bulk of protein kept constant during DES-PC whereby the quantitative changes were exclusively detected for these two acidic spots. We therefore looked at possible protein modifications for these pI variants. As pI shifts are often consistent with protein phosphorylation we gave first considerations to the phosphorylation status of AST2 using a phosphospecific protein stain. However, phosphorylation was neither detectable at the time point $C t r l 0$ nor at Des 2 (data not shown). Lysine acetylation that is postulated to occur at several amino acid sites of AST2 in mice was also investigated by mass spectrometry, but we could not confirm any acetylated peptide. The change in spot volume intensity might therefore due to other modifications.

Another remodelling effect of a specific protein isoform was observed for the most acidic spot of the UQCRC1 protein (spot \#53) that showed a significant decreased abundance after the onset of the preconditioning protocol. Here the phosphospecific protein stain indicated a phosphorylation pattern for this spot chain (Fig. 5B). The changes in protein abundance of the most acidic pI variant of UQCRC1 might occur with concomitant changes in phosphorylation.

\section{Discussion}

In the last decade there has been an effort to elucidate the molecular pathways of DESPC by deducing targets from already known signalling in IPC. Nevertheless, only fragments are known regarding the overall alterations responsible for the subsequent progression of the preconditioning signal. In our discovery-driven proteomics approach we hypothesised that expression changes in sets of proteins will correlate with differences between the experimental time points of an intermittent desflurane-preconditioning protocol. In fact the second administration of $1 \mathrm{MAC}$ desflurane accounted for the most protein alterations in the myocardial proteome (Fig. 3), whereas the minority of proteins remained altered after the last wash-out phase (Fig. 4). Interestingly, we detected changes primarily affecting proteins involved in NADH/NAD+ redox balance, calcium homeostasis and acidosis, all as part of cellular respiration (Table 1).

AST for example plays a role in amino acid metabolism, the urea and Krebs cycles where it catalyses the conversion of aspartate and alpha-ketoglutarate to oxaloacetate and glutamate. 
The cytosolic isoenzyme AST1 allows the transport of reducing equivalents across the inner mitochondrial membrane. During ischemia NADH become accumulated because $\mathrm{O}_{2}$ shortage limits NADH oxidation at the electron transport chain and lead to intracellular acidosis [20]. Interestingly, sevoflurane preconditioning has been shown to temporarily increase NADH [21]. Assuming that DES-PC also evokes a rise in NADH, the cumulative response of AST1 to the desflurane application found in this study may contribute to cardioprotection by pretriggering removal and oxidation of post-ischemic NADH. Besides AST1 we also identified the mitochondrial isoenzyme AST2 in the cytosolic protein fractions of the preconditioned heart. Mitochondrial AST2 leakage was shown to be an indicator for damage of heart mitochondria following anoxia and reoxygenation, and the degree of AST2 release depends on the duration of the preceding anoxia [22]. In I/R injury the mitochondrial enzyme AST2 was also found to be significantly increased in the cytosolic fraction, and dramatically decreased in heart mitochondria, respectively $[14,23]$. One may suggest that the repetitive administration of desflurane triggers moderate AST2 leakage into the cytosol.

The mitochondrial aconitase ACO2 has been implicated in oxidative stress regulation and cardiac I/R injury [2]. It was demonstrated that the response of ACO2 to reperfusioninduced pro-oxidant production appears to be a regulated event that is expected to reduce irreparable damage to the mitochondria during cardiac I/R [24]. In 2-DE gels ACO2 is represented by a number of redundant spots in a protein chain. A thorough analysis by Hunzinger and co-workers revealed no clear indications for the nature of pI differences observed in terms of sequence coverage [25], but ACO2 appears to be a target for carbonylation and oxidative modification [26, 27]. Its inactivation, suggested to be due to oxidative modifications, leads to an accumulation of reduced metabolites. In our DESPC study we found decreased expression of exclusively one spot in the chain of the ACO2 protein isoforms, namely the most basic spot of the protein bulk. We also identified oxidative modifications in this spot isoform, a double oxidation at tryptophan residues also referred to as $\mathrm{N}$-formylkynurenine modification (data not shown). The data do not allow concluding that ACO2 is partially inactivated by this oxidative modification. However, it might be possible that specific modified protein isoforms of ACO2 transiently unbalance the amount of NADH in the cell and therefore contribute to defence mechanisms against cardiac injuries like I/R.

The inhibition of the electron transfer leads in general to an increased generation of reactive oxygen species (ROS). ROS participate in the process of APC [28-31] particularly triggering the opening of $\mathrm{K}_{\text {ATP }}$ channels and preventing $\mathrm{Ca}^{2+}$ overload in the mitochondria $[2,32,33]$. In accordance with that we found a down-regulation of several proteins involved in electron transport chain, including the soluble complex I subunits NDUFS1 and NDUFV1, and UQCRC1 of complex III. All three spots showed the same modulation during DES-PC namely a dramatic decrease directly after the onset of the preconditioning protocol (Fig. 4). As NDUFS1 and NDUFV1 are both represented in faint protein spots we suggest them to be modified isoforms of the original protein. They showed highly divergent values for $\mathrm{Mr}$ and pI compared to the calculated values (Table 1), possibly a shift due to protein degradation or post-translational modification. As protein oxidation leads to proteolytic breakdown of a modified protein [34], oxidative modification may account for the expression changes observed for NDUFS1. The flavoprotein NDUFV1 was already found to be oxidatively modified [35]. Studying the impact of oxidative stress on mitochondria, NDUFS1 was formerly shown to decrease in cells exposed to $\mathrm{H}_{2} \mathrm{O}_{2}$ [36]. NDUFS1 was also demonstrated to undergo dioxidation of tryptophan [37]. In our study the protein isoforms of NDUFS1 and NDUFV1 thus possibly undergo oxidative modification that in turn evoked their degradation during DES-PC. These modified isoforms may contribute to the preconditioning effect by regulating $\mathrm{NADH} / \mathrm{NAD}^{+}$ redox balance. The decrease in levels of NDUFS1 has already been found to result in reduced electron transport and ROS generation [38]. The partial inhibition of complex III is already discussed to account for the cardioprotective properties of volatile anesthetics [39]. A recent proteomics study also detected decreased levels of UQCRC1 in isoflurane-preconditioned heart [16]. In accordance to this we found UQCRC1 to be diminished especially in response to the washout phases during the preconditioning protocol. This progression may contribute 
to a mild reversible suppression of the respiratory chain whereby a possible attenuation of oxygen consumption may mimic an ischemic situation.

The observed alterations are in line with commonly regulated proteins of preconditioning. Proteomic studies investigating expression changes at the end of the preconditioning protocol postulated the implication of proteins associated with glycolysis, mitochondrial respiration, and stress [40-43]. For instance Xiao and co-workers demonstrated several mitochondrial protein expression changes of proteins related to ATP generation and transport in a setup analysing delayed sevoflurane-preconditioning [15]. Bienengraeber et al. could show that isoflurane-induced preconditioning predominantly affected complexes of the electron transport chain in the cardiac mitochondrial proteome [16]. In addition, metabolomics studies strengthen the link between bioenergetic profiles and cardioprotection [40,44]. A genomics investigation also reported pattern of reduction for genes related to mitochondrial energy metabolism following repetitive ischaemia [45].

In contrast to the above mentioned omics-studies this is the first approach that investigated alterations at different experimental time points of the preconditioning protocol. It is a fact that the intermittent administration of the anaesthetic interrupted by a memory phase prior to the insult is an important component of the preconditioning effect (for review see [46-48]). However, the precise threshold and duration that must be achieved to trigger the protective effect has not been established. For APC in particular there is certain evidence that the reduction of ischemia-reperfusion injuries depends on timing and the threshold of repetitive application $[4,8]$. Our proteomics data underline the impact of repetitive agent application as demonstrated by the cumulative effect of protein changes (Fig. 3). According to the general paradigm of preconditioning, each stimulus initiates the release of 1 or more triggers from the myocardium including, most notably, adenosine, bradykinin, and opioids. These triggers bind to their respective G-protein-coupled receptors on the cardiomyocyte membranes and activate in parallel multiple, complex (and possibly redundant) signalling pathways. These signals are proposed to converge on the mitochondria and confer myocardial protection by stabilizing the mitochondrial membranes, inhibiting the opening of large-diameter conductance channels (mitochondrial permeability transition pores) and thereby attenuating the swelling and rupture of mitochondria (for review see $[46,49,50]$ ). The final pathway therefore seems to lie within the mitochondrial cellular structure and the electron transfer chain. This complex response clearly illustrates that preconditioning is a multimodal myocardial protection strategy. To our knowledge, until now our study is the only one that explored the timing of the different pathways to date. Interestingly, the protein alterations found in our study predominantly occurred after the second administration of the trigger and encompass proteins that are involved in NADH/NAD+ redox balance, calcium homeostasis and acidosis, all modulators of cellular activity. From this treatment-dependent regulation we suppose that 1 ) a repetitive stimulation is necessary to amplify the signalling cascade, 2) signalling is rapidly transmitted to the effector site and 3) proteins undergo changes that transiently remodel cellular activity. Thus only the minority of proteins has to remain altered at the end of the preconditioning protocol where actually the ischemic insult will be in place. Our data therefore substantiate a reversible remodelling of metabolic proteins that occur upon desflurane administration but decline at the end of the protocol. Interestingly, Burwell et al. already characterized cardioprotection by a metabolic shutdown and gradual wake-up [51].

Diverse kinds of protein modifications to specific (spot) isoforms seem here to play an important role as the detected expression changes appeared only for specific and not for all isoforms of the respective protein. For instance (1) CA1 and CA2 represented different members of the same protein family, (2) AST2, UQCRC1 and ACO2 were among spot chains, and (3) NDUFS1 and NDUFV1 were located at different positions in the gel than theoretically expected. Nevertheless, differences in protein abundance like for AST2, or phosphorylation state in the case of UQCRC1 (Fig. 5) do not necessarily indicate changes in the proteins' overall function. They rather represent secondary changes of the myocardial proteome in response to the preconditioning stimulus itself. Nevertheless, when studying the literature 
in the general context of cardiovascular proteomics we came upon a hit parade of repeatedly identified proteins, mostly involving glycolytic enzymes, heat shock, and stress proteins as well as cytoskeletal components from human, mouse and rat tissues [52]. We therefore suggest that the reported protein changes in our and other proteomic-based preconditioning studies are probably less specific for the treatment but rather demonstrate a synergistic effect of cellular and molecular targets to adapt to acute or upcoming metabolic stress. In this way, APC and IPC induced changes of bioenergetic proteins may build up a common protective-adaptive state in the heart and thereby precondition for upcoming I/R events.

It should be mentioned that all volatile anaesthetics have cardiodepressive effects by decreasing the oxygen requirements of the myocardium. A proteomic study of postanaesthetised rats revealed to this plenty protein expression changes up to 72 hours of desflurane anaesthesia [53]. Kalenka et al. showed a two-fold change in 106 different proteins predominantly associated with glycolysis, mitochondrial respiration, and stress. Nevertheless, only one protein isoform (NDUFS1) was found to be affected both in our study by intermitted short-term administration (DES-PC) and by long-term exposure (desflurane anaesthesia) in the post-anaesthesia study. In fact, the haemodynamic data of our experiments for infarct size measurements [5] stresses that heart rate and mean aortic pressure were reduced during the periods of desflurane. The treatment-dependent modulation of proteins affected by DES-PC might therefore be due to the volatile anaesthetic itself and substantiate the effect of the preconditioning protocol. However whether the reported protein expression changes resulted from these concomitant alterations in haemodynamic function or whether the transient proteomic profiles are the reason for the decreased oxygen demand, cannot be concluded from the present data and remains to be investigated.

In conclusion, proteomic analyses have the potential to identify previously uncharacterised mediators in cardioprotective signalling, or as demonstrated in the current study, uncover similar regulation of proteins affected by specific treatments. Thus the proteomics data now enables to exploit specific physiological relationships between different (groups) of proteins in the context of anaesthetic preconditioning. Here further research needs to be carried out especially to elucidate other posttranslational modifications as well as to assay enzyme activity (like complex 1, aspartate aminotransferase). But these investigations are beyond the scope of the current study.

\section{Conflict of Interest}

The authors have nothing to disclose.

\section{Acknowledgements}

This work was supported by the Deutsche Forschungsgemeinschaft (Bonn, Germany) within the Research Training Group GRK1089. A research fellowship was provided from the JUERGEN MANCHOT STIFTUNG (Düsseldorf, Germany) to N.D.R.

\section{References}

1 Lu X, Moore PG, Liu H, Schaefer S: Phosphorylation of ARC is a critical element in the antiapoptotic effect of anesthetic preconditioning. Anesth Analg 2011;112:525-531.

2 Sedlic F, Pravdic D, Ljubkovic M, Marinovic J, Stadnicka A, Bosnjak ZJ: Differences in production of reactive oxygen species and mitochondrial uncoupling as events in the preconditioning signaling cascade between desflurane and sevoflurane. Anesth Analg 2009;109:405-411. 


\section{Cellular Physiology Cell Physiol Biochem 2014;33:967-981 and Biochemisty \begin{tabular}{l|l} 
DOI: 10.1159/000358668 2014 S. Karger AG, Basel & (c)
\end{tabular} \\ Dyballa-Rukes et al.:Proteomic Analysis of Desflurane Preconditioning}

3 Redel A, Lange M, Jazbutyte V, Lotz C, Smul TM, Roewer N, Kehl F: Activation of mitochondrial largeconductance calcium-activated $\mathrm{K}^{+}$channels via protein kinase A mediates desflurane-induced preconditioning. Anesth Analg 2008;106:384-391.

4 Smul TM, Lange M, Redel A, Burkhard N, Roewer N, Kehl F: Desflurane-induced preconditioning against myocardial infarction is mediated by nitric oxide. Anesthesiology 2006;105:719-725.

-5 Toma O, Weber NC, Wolter JI, Obal D, Preckel B, Schlack W: Desflurane preconditioning induces timedependent activation of protein kinase $\mathrm{C}$ epsilon and extracellular signal-regulated kinase 1 and 2 in the rat heart in vivo. Anesthesiology 2004;101:1372-1380.

-6 Ebel D, Müllenheim J, Südkamp H, Bohlen T, Ferrari J, Huhn R, Preckel B, Schlack W: Role of tyrosine kinase in desflurane-induced preconditioning. Anesthesiology 2004;100:555-561.

7 Bein B, Renner J, Caliebe D, Hanss R, Bauer M, Fraund S, Scholz J: The effects of interrupted or continuous administration of sevoflurane on preconditioning before cardio-pulmonary bypass in coronary artery surgery: comparison with continuous propofol. Anaesthesia 2008;63:1046-1055.

8 Frässdorf J, Borowski A, Ebel D, Feindt P, Hermes M, Meemann T, Weber R, Müllenheim J, Weber NC, Preckel B, Schlack W: Impact of preconditioning protocol on anesthetic-induced cardioprotection in patients having coronary artery bypass surgery. J Thorac Cardiovasc Surg 2009;137:1436-1442.

-9 Meco M, Cirri S, Gallazzi C, Magnani G, Cosseta D: Desflurane preconditioning in coronary artery bypass graft surgery: a double-blinded, randomised and placebo-controlled study. Eur J Cardio-Thorac Surg 2007;32:319-325.

10 Piriou V, Chiari P, Lhuillier F, Bastien O, Loufoua J, Raisky O, David JS, Ovize M, Lehot JJ: Pharmacological preconditioning: comparison of desflurane, sevoflurane, isoflurane and halothane in rabbit myocardium. Br J Anaesth 2002;89:486-491.

11 Lotz C, Fisslthaler B, Redel A, Smul TM, Stumpner J, Pociej J, Roewer N, Fleming I, Kehl F, Lange M: Activation of adenosine-monophosphate-activated protein kinase abolishes desflurane-induced preconditioning against myocardial infarction in vivo. J Cardiothorac Vasc Anesth 2011;25:66-71.

12 Lange M, Smul TM, Redel A, Lotz C, Jazbutyte V, Schnupp V, Roewer N, Kehl F: Differential role of calcium/ calmodulin-dependent protein kinase II in desflurane-induced preconditioning and cardioprotection by metoprolol: metoprolol blocks desflurane-induced preconditioning. Anesthesiology 2008;109:72-80.

13 Stumpner J, Redel A, Kellermann A, Lotz CA, Blomeyer CA, Smul TM, Kehl F, Roewer N, Lange M: Differential role of Pim-1 kinase in anesthetic-induced and ischemic preconditioning against myocardial infarction. Anesthesiology 2009;111:1257-1264.

14 Feng J, Zhu M, Schaub MC, Gehrig P, Roschitzki B, Lucchinetti E, Zaugg M: Phosphoproteome analysis of isoflurane-protected heart mitochondria: phosphorylation of adenine nucleotide translocator-1 on Tyr194 regulates mitochondrial function. Cardiovasc Res 2008;80:20-29.

15 Xiao Y-Y, Chang Y-T, Ran K, Liu J-P: Delayed preconditioning by sevoflurane elicits changes in the mitochondrial proteome in ischemia-reperfused rat hearts. Anesth Analg 2011;113:224-232.

-16 Bienengraeber M, Pellitteri-Hahn M, Hirata N, Baye TM, Bosnjak ZJ, Olivier M: Quantitative characterization of changes in the cardiac mitochondrial proteome during anesthetic preconditioning and ischemia. Physiol Genomics 2013;45:163-170.

17 Lowry OH, Rosebrough NJ, Farr AL, Randall RJ: Protein measurement with the Folin phenol reagent. J Biol Chem 1951;193:265-275.

18 Kang D, Gho YS, Suh M, Kang C: Highly sensitive and fast protein detection with Coomassie Brilliant Blue in sodium dodecyl sulfate-polyacrylamide gel electrophoresis. Bull Korean Chem Soc 2002;23:1511-1512.

19 Dyballa N, Metzger S: Fast and sensitive colloidal coomassie G-250 staining for proteins in polyacrylamide gels. J Vis Exp. 2009;(30). pii: 1431. doi: 10.3791/1431

20 Riess ML, Camara AKS, Kevin LG, An J, Stowe DF: Reduced reactive $\mathrm{O}_{2}$ species formation and preserved mitochondrial NADH and $\left[\mathrm{Ca}^{2+}\right]$ levels during short-term 17 degrees $\mathrm{C}$ ischemia in intact hearts. Cardiovasc Res 2004;61:580-590.

21 Riess ML, Camara AKS, Chen Q Novalija E, Rhodes SS, Stowe DF: Altered NADH and improved function by anesthetic and ischemic preconditioning in guinea pig intact hearts. Am J Physiol Heart Circ Physiol 2002;283:H53-60.

22 Nishimura M, Takami H, Kaneko M, Nakano S, Matsuda H, Kurosawa K, Inoue T, Tagawa K: Mechanism of mitochondrial enzyme leakage during reoxygenation of the rat heart. Cardiovasc Res 1993;27:1116-1122. 


\section{Cellular Physiology Cell Physiol Biochem 2014;33:967-981 and Biochemistry \\ Dyballa-Rukes et al.:Proteomic Analysis of Desflurane Preconditioning}

-23 Ouyang Y-B, Kuroda S, Kristián T, Siesjö BK: Release of mitochondrial aspartate aminotransferase (mAST) following transient focal cerebral ischemia suggests the opening of a mitochondrial permeability transition pore. Neurosci Res Commun 1997;20:167-173.

-24 Bulteau A-L, Lundberg KC, Ikeda-Saito M, Isaya G, Szweda LI: Reversible redox-dependent modulation of mitochondrial aconitase and proteolytic activity during in vivo cardiac ischemia/reperfusion. Proc Natl Acad Sci 2005;102:5987-5991.

25 Hunzinger C, Wozny W, Schwall GP, Poznanović S, Stegmann W, Zengerling H, Schoepf R, Groebe K, Cahill MA, Osiewacz HD, Jägemann N, Bloch M, Dencher NA, Krause F, Schrattenholz A: Comparative profiling of the mammalian mitochondrial proteome: multiple aconitase- 2 isoforms including $\mathrm{N}$-formylkynurenine modifications as part of a protein biomarker signature for reactive oxidative species. J Proteome Res 2006;5:625-633.

26 Yarian CS, Rebrin I, Sohal RS: Aconitase and ATP synthase are targets of malondialdehyde modification and undergo an age-related decrease in activity in mouse heart mitochondria. Biochem Biophys Res Commun 2005;330:151-156.

27 Yarian CS, Sohal RS: In the aging housefly aconitase is the only citric acid cycle enzyme to decline significantly. J Bioenerg Biomembr 2005;37:91-96.

28 Hanouz J-L, Zhu L, Lemoine S, Durand C, Lepage O, Massetti M, Khayat A, Plaud B, Gérard J-L: Reactive oxygen species mediate sevoflurane- and desflurane-induced preconditioning in isolated human right atria in vitro. Anesth Analg 2007;105:1534-1539, table of contents.

29 Müllenheim J, Ebel D, Frässdorf J, Preckel B, Thämer V, Schlack W: Isoflurane preconditions myocardium against infarction via release of free radicals. Anesthesiology 2002;96:934-940.

-30 Riess ML, Kevin LG, McCormick J, Jiang MT, Rhodes SS, Stowe DF: Anesthetic preconditioning: the role of free radicals in sevoflurane-induced attenuation of mitochondrial electron transport in Guinea pig isolated hearts. Anesth Analg 2005;100:46-53.

-31 Tanaka K, Weihrauch D, Kehl F, Ludwig LM, LaDisa JF, Kersten JR, Pagel PS, Warltier DC: Mechanism of preconditioning by isoflurane in rabbits: a direct role for reactive oxygen species. Anesthesiology 2002;97:1485-1490.

-32 Novalija E, Varadarajan SG, Camara AKS, An J, Chen Q, Riess ML, Hogg N, Stowe DF: Anesthetic preconditioning: triggering role of reactive oxygen and nitrogen species in isolated hearts. Am J Physiol Heart Circ Physiol 2002;283:H44-52.

-33 Tanaka K, Kehl F, Gu W, Krolikowski JG, Pagel PS, Warltier DC, Kersten JR: Isoflurane-induced preconditioning is attenuated by diabetes. Am J Physiol Heart Circ Physiol 2002;282:H2018-2023.

34 Dean RT, Fu S, Stocker R, Davies MJ: Biochemistry and pathology of radical-mediated protein oxidation. Biochem J 1997;324:1-18.

-35 Wen J-J, Garg N: Oxidative modification of mitochondrial respiratory complexes in response to the stress of Trypanosoma cruzi infection. Free Radic Biol Med 2004;37:2072-2081.

-36 Sweetlove LJ, Heazlewood JL, Herald V, Holtzapffel R, Day DA, Leaver CJ, Millar AH: The impact of oxidative stress on Arabidopsis mitochondria. Plant J Cell Mol Biol 2002;32:891-904.

-37 Møller IM, Kristensen BK: Protein oxidation in plant mitochondria detected as oxidized tryptophan. Free Radic Biol Med 2006;40:430-435.

- 38 Iuso A, Scacco S, Piccoli C, Bellomo F, Petruzzella V, Trentadue R, Minuto M, Ripoli M, Capitanio N, Zeviani M, Papa S: Dysfunctions of Cellular Oxidative Metabolism in Patients with Mutations in the NDUFS1 and NDUFS4 Genes of Complex I. J Biol Chem 2006;281:10374-10380.

- 39 Falk MJ, Kayser E-B, Morgan PG, Sedensky MM: Mitochondrial Complex I Function Modulates Volatile Anesthetic Sensitivity in C. elegans. Curr Biol 2006;16:1641-1645.

40 Mayr M, Liem D, Zhang J, Li X, Avliyakulov NK, Yang JI, Young G, Vondriska TM, Ladroue C, Madhu B, Griffiths JR, Gomes A, Xu Q Ping P: Proteomic and metabolomic analysis of cardioprotection: Interplay between protein kinase $\mathrm{C}$ epsilon and delta in regulating glucose metabolism of murine hearts. J Mol Cell Cardiol 2009;46:268-277.

41 Perrelli M-G, Pagliaro P, Penna C: Ischemia/reperfusion injury and cardioprotective mechanisms: Role of mitochondria and reactive oxygen species. World J Cardiol 2011;3:186-200.

42 Wong R, Aponte AM, Steenbergen C, Murphy E: Cardioprotection leads to novel changes in the mitochondrial proteome. Am J Physiol Heart Circ Physiol 2010;298:H75-91. 


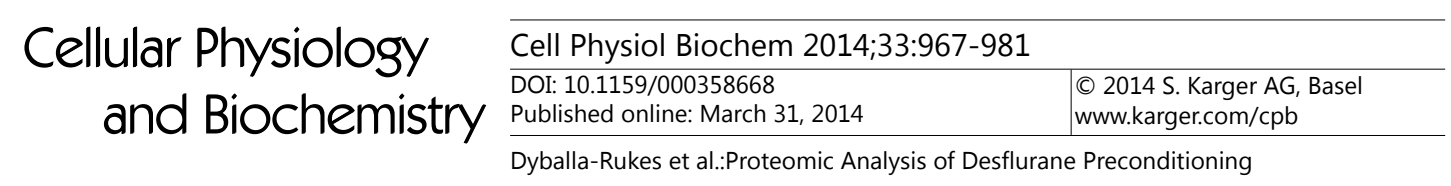

43 Arrell DK, Elliott ST, Kane LA, Guo Y, Ko YH, Pedersen PL, Robinson J, Murata M, Murphy AM, Marbán E, Van Eyk JE: Proteomic analysis of pharmacological preconditioning: novel protein targets converge to mitochondrial metabolism pathways. Circ Res 2006;99:706-714.

44 Wang L, Ko KWS, Lucchinetti E, Zhang L, Troxler H, Hersberger M, Omar MA, Posse de Chaves EI, Lopaschuk GD, Clanachan AS, Zaugg M: Metabolic profiling of hearts exposed to sevoflurane and propofol reveals distinct regulation of fatty acid and glucose oxidation: CD36 and pyruvate dehydrogenase as key regulators in anesthetic-induced fuel shift. Anesthesiology 2010;113:541-551.

45 Shen Y-T, Depre C, Yan L, Park JY, Tian B, Jain K, Chen L, Zhang Y, Kudej RK, Zhao X, Sadoshima J, Vatner DE, Vatner SF: Repetitive ischemia by coronary stenosis induces a novel window of ischemic preconditioning. Circulation 2008;118:1961-1969.

46 De Hert SG, Preckel B, Hollmann MW, Schlack WS: Drugs mediating myocardial protection. Eur J Anaesthesiol 2009;26:985-995.

47 Hu Z-Y, Liu J: Mechanism of cardiac preconditioning with volatile anaesthetics. Anaesth Intensive Care 2009;37:532-538.

48 Przyklenk K: Reduction of myocardial infarct size with ischemic "conditioning": physiologic and technical considerations. Anesth Analg 2013;117:891-901.

49 Frässdorf J, De Hert S, Schlack W: Anaesthesia and myocardial ischaemia/reperfusion injury. Br J Anaesth 2009;103:89-98.

50 Landoni G, Fochi O, Tritapepe L, Guarracino F, Belloni I, Bignami E, Zangrillo A: Cardiac protection by volatile anesthetics. A review. Minerva Anestesiol 2009;75:269-273.

51 Burwell LS, Nadtochiy SM, Brookes PS: Cardioprotection by metabolic shut-down and gradual wake-up. J Mol Cell Cardiol 2009;46:804-810.

-52 Petrak J, Ivanek R, Toman 0, Cmejla R, Cmejlova J, Vyoral D, Zivny J, Vulpe CD: Déjà vu in proteomics. A hit parade of repeatedly identified differentially expressed proteins. Proteomics 2008;8:1744-1749.

-53 Kalenka A, Maurer MH, Feldmann RE, Kuschinsky W, Waschke KF: Volatile anesthetics evoke prolonged changes in the proteome of the left ventricule myocardium: defining a molecular basis of cardioprotection? Acta Anaesthesiol Scand 2006;50:414-427. 